\title{
A Profile-Based Identification of Standby and Useless Electricity Consumption in Buildings
}

\author{
Rien De Koster \\ Irex-Consulting \\ Brussels, Belgium \\ rien.dekoster@irex-consulting.com
}

\author{
Juan Van Roy and Johan Driesen \\ Department of Electrical Engineering (ESAT), Division ELECTA \\ University of Leuven (KU Leuven) \\ Leuven, Belgium \\ Juan.VanRoy@esat.kuleuven.be
}

\begin{abstract}
Useless electricity consumption is the electricity consumption of an electric appliance or system that is not performing its primary function or that is performing its primary function without being useful. So, useless electricity consumption does not only consist of standby losses. To identify the useless electricity consumption in a building, a profile-based approach is developed. This approach is used to investigate the useless electricity consumption in five buildings of the University of Leuven. The result of this study is that in these buildings the useless electricity consumption accounts for 4 to $13 \%$ of the total electricity consumption. This paper will give a detailed discussion of a case study in a library of the university.
\end{abstract}

Index Terms-Standby losses; Useless electricity consumption; Leaking electricity; Energy conservation; Energy efficiency.

\section{INTRODUCTION}

$\mathbf{T}$ HE European Commission has set the climate and energy targets with some ambitious targets for 2020, also better known as the 20/20/20 targets [1]. One of the three targets is a $20 \%$ improvement in the EU's energy efficiency compared to a business-as-usual scenario. Also, as per recent European directive, by 2020 all new buildings and large renovations need to lead to nearly zero energy buildings which should lead to a higher penetration of local renewable energy resources and energy efficiency [2].

Energy efficiency can be reached by e.g. the use of more efficient technologies, such as heat pumps (HPs) and electric vehicles (EVs) and the reduction in energy consumption. Reducing the energy consumption means not only eliminating standby losses, but all useless energy consumption.

\section{A. Standby losses}

Because of the increase of the number of electric appliances, standby power consumption is no longer negligible with respect to the total electricity consumption in households, office buildings, etc. It is not easy to define the term standby losses and many definitions exist. Traditionally, literature on useless electricity consumption research deals only with standby power consumption [3]-[5]. Standby power consumption is defined as the electricity consumption of an appliance when it is in standby mode or in off-mode. Standby power losses are small for each individual appliance, but they are no longer negligible when these losses are aggregated.
According to [3], the standby power consumption in OECD countries accounts for 3 to $13 \%$ of the annual electricity consumption of a household. For an average household this means a continuous power demand of 20 to $60 \mathrm{~W}$. This translates to a share of about $2 \%$ in the total electricity consumption of the OECD countries [4]. In Belgium, standby power consumption is responsible for $8 \%$ of the yearly electricity consumption of a household [5]. For European household, standby losses account for $14 \%$ for households [6], whereas in California standby power consumptions accounts for 5 to $26 \%$ of the total electricity consumption [7].

In office buildings it is more difficult to calculate the standby losses because of the increased diversity and large number of electric appliances. Different calculation approaches are chosen in literature. For instance, a Swiss study assumes that all electricity consumption outside the working hours can be accounted to standby losses. During the regular working hours all consumption is assumed to be usefull. Under these assumptions, about $36 \%$ of the weekly electricity consumption is allocated to the standby losses [8]. However, there are always some appliances that are also contributing to the standby losses during working hours and not all the consumption outside the working hours can be considered as useless consumption (e.g. dataservers).

A global initiative to reduce the standby power consumption is the One watt initiative [9]. The initiative consisted of a plan that standby losses of appliances would be reduced to $1 \mathrm{~W}$ or lower by 2010 . Each country had to develop a strategy to achieve this goal. A European Regulation (EC 1275/2008) gives regulations on the electricity consumption of electrical and electronic household and office equipment in standby and off-mode [10]. According to this EC, the standby losses are limited to $1 \mathrm{~W}$ since 2010 and $0.5 \mathrm{~W}$ in 2013 . If the appliance also shows information or its state, than this limit is doubled to $2 \mathrm{~W}$ and $1 \mathrm{~W}$ respectively.

\section{B. Definition of useless electricity consumption}

There are also appliances that contribute to useless electricity consumption when these are performing their primary function during e.g. regular working hours or outside regular working hours. Therefore, useless electricity 
consumption involves more than only standby power consumption.

Useless electricity consumption can be defined as the electricity consumption of an electric appliance or system when it is not performing its primary function (e.g. standby of off-mode) or when it is performing its primary function without being useful. As a result, also lighting, ICT appliances, installations for heating, ventilation and cooling (HVAC), etc. can contribute to the useless electricity consumption.

An overview of different operation modes of an appliance is given in [9] and [11]. The distinction in modes is based on the appliance function, hierarchy of energy demand, time durations, etc.

\section{Power demand profile of the KU Leuven}

The power demand profile of the KU Leuven is shown in Fig. 1. This profile includes the total power consumption of all 303 buildings of the KU Leuven. The maximum power demand is about 9.5 MW, while there is a large base load of about $4 \mathrm{MW}$. This base load is mainly caused by electric appliances which are fed continuously from the electricity grid. The weekly electricity consumption corresponds to $1000 \mathrm{MWh}$, of which about $220 \mathrm{MWh}$ is consumed during the weekend. The majority of the buildings is not or less frequently used during the weekends. Therefore, it can be predicted that a significant amount of the total electricity consumption can be allocated as useless electricity consumption.

\section{Scope of the paper}

This paper examines the identification and calculation of the useless electricity consumption in buildings. Therefore, a profile-based approach is developed to investigate the useless electricity consumption of buildings [12]. A case-study was performed at the University of Leuven (KU Leuven) in Belgium. Five representative building types for a university were investigated: a library, a college building, an office building, a laboratory and a student residence.

In this paper, first the profile-based approach will be explained in Section II. The case study of the library will be discussed in Section III as an illustration of this profile-based approach. To conclude, in Section IV the most important results of the other buildings will be given.

\section{Methodology: A Profile-Based Approach}

A profile-based approach is developed to identify the different electric appliances or systems that contribute to the useless electricity consumption of a building. This is done by setting up a weekly power demand profile for each individual appliance. But this approach is not limited to a time period of one week. An analysis of this profile can identify when the electricity consumption is useful or useless.

Thus, this profile-based approach allows to give an indication of the useless electricity consumption of each appliance. By combining the results for all appliances or systems in the building, it is possible to determine the total useless electricity consumption.

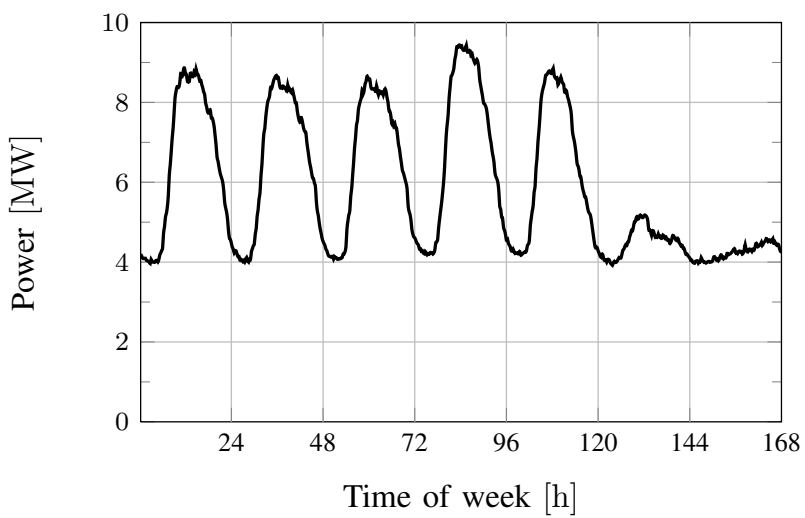

Fig. 1. Weekly power demand of the KU Leuven (Monday to Sunday).

In the ideal case, the profile-based approach requires a profile of each appliance or system in the building. But practically, due to the large number of electric appliances in a building, it may be difficult to measure each individual appliance. Therefore, only the appliances that might contribute to the useless electricity consumption of a building are considered in this study. The profile of these appliances is measured or the profile is defined by a combination of measurements and assumptions on the use. These appliances are determined by screening the building, especially outside regular working hours, and by communicating with the employees.

For each of the appliances that may contribute to the useless electricity consumption, a measurement is carried out to determine a weekly profile. Due to the large diversity of electric appliances and their power demand, these appliances are divided into seven categories.

- ICT: Electric appliances to support the IT infrastructure, e.g. servers, wireless networks, switches, etc. However, computers are part of the public and/or non-public areas.

- Public areas: Electrical appliances in public areas such as hallways, auditoriums or kitchens, etc.

- Non-public areas: Electrical appliances in non-public areas such as offices, laboratories or student rooms.

- HVAC: Electrical installations for the heating, ventilation and cooling of the building.

- Lighting: Electricity consumption of the lighting installation.

- Residual consumption: Electrical appliances that are not considered in the previous categories. This residual consumption is calculated as the difference of the overall building electricity consumption and the consumption of the appliances in the previous categories.

- Losses: Losses in the electricity grid, calculated as $1.4 \%$ of the power demand of the building [13].

Keep in mind that appliances which are considered not to contribute to the useless electricity consumption are part of the residual consumption. This means that e.g. a part of the lighting is considered to be useful during the whole period 
and is considered as part of the residual consumption, while the other part may be responsible for a part of the useless electricity consumption and therefore is part of the lighting category.

For the case studies in this paper, it is important to note that only a limited number of appliances or systems are considered. Although the measurements are focused on appliances that contribute to the useless electricity consumption, it is possible that some appliances might not be taken into account. Therefore, the results in this paper of the profile-based analysis give an indication of the minimal share of useless electricity of the building.

The measurements are performed with several measurement appliances. The uncertainty on the measurements have been taken into account in all calculations. To analyze the use of lighting, light-sensitive diodes are used.

\section{CASe Study: A University Library}

The profile-based approach is used for the analysis of five buildings at the KU Leuven. Here, one of the libraries of the university is discussed in detail to illustrate the profile-based approach.

\section{A. Power demand and building characteristics}

The profile of the library is shown in Fig. 2 during a period of one week. The corresponding electricity consumption is $8554 \pm 44 \mathrm{kWh}$. The library is opened from Monday till Friday between 9 am and $10 \mathrm{pm}$ and from 9 am to $1 \mathrm{pm}$ on Saturday. During opening hours, a remarkable increase in the electricity consumption is noticed. When the library is closed, the power drops from a maximum value of $83 \pm 1.4 \mathrm{~kW}$ around noon to the base load of $18 \pm 1.1 \mathrm{~kW}$.

The building can be divided in two wings. The first one consists of the administrative services with mainly offices and meeting rooms. The second wing consists of the library area. In addition, there are some specific rooms, such as a computer room and some meeting rooms.

\section{B. Profile-based approach of the library}

The screening of the library and the communication with the employees resulted in the identification of the appliances or systems that contribute to the useless electricity consumption. These appliances are divided into seven categories. The power consumption profiles of these categories are illustrated in Fig. 3. This section discusses the results of the profile-based approach of this building.

1) ICT: ICT appliances which may contribute to the useless electricity consumption include servers, the alarm system, switches, the wireless network, etc. Also the cooling installation for the server room is included, since it is specifically used for the cooling of the servers.

The total installed power for ICT appliances is $4.5 \pm 1.1 \mathrm{~kW}$, of which $4 \pm 1 \mathrm{~kW}$ is attributed to the server room. As these appliances need to work continuously, ICT contributes to the base load of the profile in Fig. 3. Measurements have shown that the electricity consumption

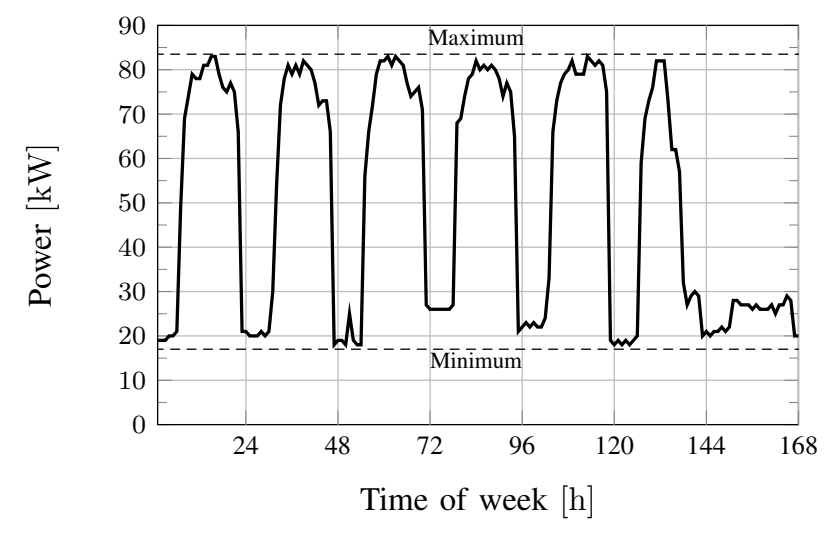

Fig. 2. Measured power demand profile of the library during a period of one week (Monday to Sunday).

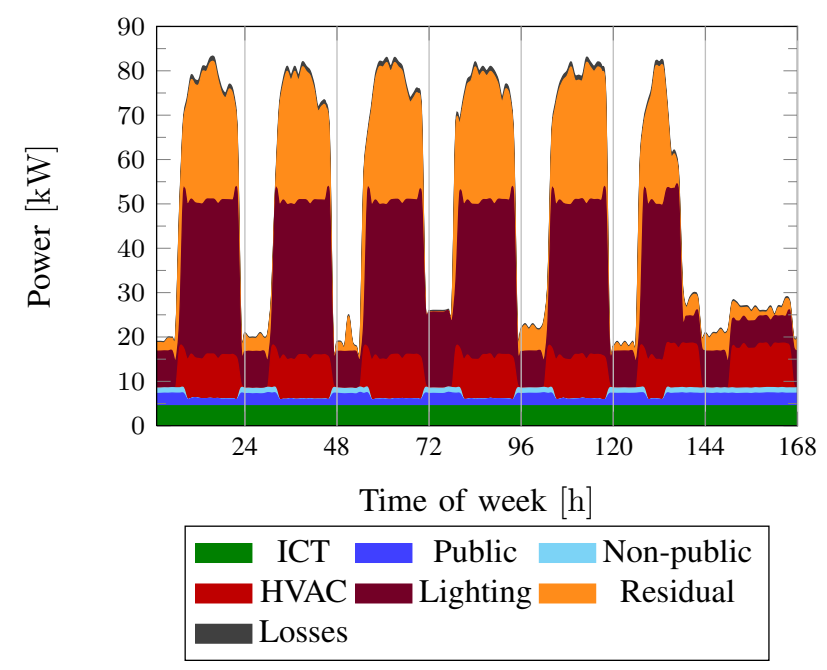

Fig. 3. Weekly power demand for the seven categories of the library, according to the profile-based approach.

is nearly constant throughout the day. Therefore, this consumption is assumed to be constant. This results in a total weekly electricity consumption of $756 \pm 185 \mathrm{kWh}$.

A screening of the ICT infrastructure has shown that at least one server is superfluous, as the tasks of this server could easily be transferred to other servers. The limited heat production of the other servers makes it also possible to eliminate the cooling system of the servers. Therefore, the corresponding weekly useless electricity consumption of the ICT infrastructure amounts for $480 \pm 235 \mathrm{kWh}$.

2) Public areas: The electrical appliances in public areas cover the appliances in the part of the library that is publicly accessible to every visitor. A screening of the library has shown that some computers, computer screens, copiers and scanners are not completely switched off outside regular opening hours. The total power of these appliances is $1.4 \pm 0.2 \mathrm{~kW}$.

The diversity and large number of appliances make it 
difficult to set up a profile for each individual appliance. Therefore, only the electricity consumption of the appliances outside regular opening hours, which contribute to the useless electricity consumption, is considered. During opening hours, the electricity consumption of these appliances is assumed to be useful. An exception must be made for the vending machines which need to cool some drinks and food continuously. This could not be considered as useless.

The weekly useless electricity consumption of appliances in public areas amounts to $126 \pm 22 \mathrm{kWh}$. The demand profile in Fig. 3 also includes the electricity demand of the vending machines, which is assumed to be useful. However, a large difference in consumption is observed between the different vending machines, but the possible impact on the useless electricity consumption is not taken into account.

3) Non-public areas: The electric appliances in non-public areas cover the appliances in the part of the library that is only accessible to the employees. A screening has shown that some computers, computer screens and printers in offices are not completely switched off outside regular working hours. Some other systems, like the audio-system or the submission system for books, are not switched off when closing the library. The total power of these appliances is $1.2 \pm 0.2 \mathrm{~kW}$.

The diversity and large number of appliances make it difficult to set up a profile for each individual appliance. Therefore, only the electricity consumption of these appliances outside regular opening hours, which contribute to the useless electricity consumption, is considered. During opening hours, the electricity consumption of these appliances is assumed to be useful.

Fig. 3 shows only the demand profile of the useless electricity consumption in the non-public areas. As mentioned before, the rest of the consumption is taken into account in the residual consumption. The corresponding weekly useless electricity consumption of appliances in non-public areas amounts to $101 \pm 15 \mathrm{kWh}$.

4) HVAC: The heating and ventilation system has two different heating modes, namely the normal operating mode with heating and ventilation between 6 am and $10 \mathrm{pm}$, and a holiday mode with no heating or ventilation. However, during regular closing days (Saturday afternoon and Sunday), the HVAC is operated in normal mode.

Thus, the analysis of the HVAC consumption profile in Fig. 3 shows a remarkable amount of energy consumed outside regular opening hours on Saturday afternoon and on Sunday. The increase in demand on Sunday is only due to the activation of the HVAC systems. The weekly electricity consumption amounts to $1071 \pm 277 \mathrm{kWh}$.

The electricity consumption of the HVAC systems outside the regular opening hours can be considered as useless electricity consumption as nobody is present in the library at these moments. The weekly useless electricity consumption of appliances for HVAC is $242 \pm 64 \mathrm{kWh}$.

Another advantage of avoiding this useless electricity consumption is the decrease in natural gas consumption. However, it must also be noted that switching the heating completely off may have a negative impact on the electricity and gas consumption on Monday morning.

5) Lighting: The demand profile of the lighting installations in Fig. 3 only shows the consumption of the lighting in the public areas. A screening of the library has shown that the employees switch off the lights in their office outside regular working hours. Therefore, the lighting in these non-public areas contributes to the residual consumption.

During opening hours, all lighting is switched on. The total power is $34.9 \pm 3.5 \mathrm{~kW}$, resulting in a weekly electricity consumption of $3682 \pm 368 \mathrm{kWh}$. Outside opening hours, one part of the lighting installation $(6.2 \pm 0.6 \mathrm{~kW})$ is never switched off, as it is necessary for the surveillance system during the night. The outdoor lighting $(2.2 \pm 0.2 \mathrm{~kW})$ is switched by means of a light sensor.

When closing the library on Saturday evening, it is observed that the lighting, which is required for the surveillance system, is also switched on during daytime on Sunday. The corresponding electricity consumption during the day on Sunday is assumed to be useless. The profile in Fig. 3 also shows that a part of the lighting installation was not fully switched off on Wednesday night. The surplus electricity consumption $(80 \pm 8 \mathrm{kWh}$ ) compared to other evenings is considered as useless. The total weekly useless electricity consumption of the lighting is $166 \pm 17 \mathrm{kWh}$.

6) Residual consumption: The residual consumption covers the consumption of electric appliances or systems that are not considered in the above categories. It is mainly covered by the electricity consumption of lighting in offices, appliances during regular working hours or student laptops. It is assumed that this residual consumption does not contribute to the useless electricity consumption.

7) Losses: The losses in the electricity grid of the library are calculated as $1.4 \%$ of the consumed power [13]. This corresponds to a weekly electricity consumption of $120 \pm 3 \mathrm{kWh}$. Useless electricity consumption is responsible for a part of these losses. Eliminating the useless electricity consumption reduces the losses with about $16 \mathrm{kWh}$.

\section{Overview results of the library}

An overview of all results is given in Table I. The weekly useless electricity consumption is $1115 \mathrm{kWh}$, which corresponds to $13 \%$ of the total weekly electricity consumption in the library. The majority of this useless electricity consumption, about $43 \%$, is due to ICT appliances. The HVAC of the library on Saturday afternoon and on Sunday is responsible for $22 \%$ of the useless electricity consumption. The lighting accounts for $15 \%$ of the total useless electricity consumption. Electrical appliances in public and non-public areas cover respectively $11 \%$ and $9 \%$ of the useless electricity consumption in the investigated library.

Fig. 4 illustrates the change in the weekly power demand of the library if all the useless electricity consumption is eliminated. The baseload decreases about $7 \mathrm{~kW}$, while on Sunday the baseload can be reduced to only $4 \mathrm{~kW}$. 
TABLE I

OVERVIEW OF THE WEEKLY USELESS ELECTRICITY CONSUMPTION IN A LIBRARY AND ITS SHARE IN THE TOTAL USELESS ELECTRICITY CONSUMPTION OF THE BUILDING.

\begin{tabular}{lcc}
\hline Category & $\begin{array}{r}\text { Useless electricity } \\
\text { consumption }\end{array}$ & $\begin{array}{c}\text { Share in total useless } \\
\text { electricity consumption }\end{array}$ \\
\hline ICT & $480 \pm 235 \mathrm{kWh}$ & $43 \%$ \\
Public & $126 \pm 22 \mathrm{kWh}$ & $11 \%$ \\
Non-public & $101 \pm 15 \mathrm{kWh}$ & $9 \%$ \\
HVAC & $242 \pm 64 \mathrm{kWh}$ & $22 \%$ \\
Lighting & $166 \pm 17 \mathrm{kWh}$ & $15 \%$ \\
\hline Total & $1115 \pm 353 \mathrm{kWh}$ & $100 \%$ \\
\hline
\end{tabular}

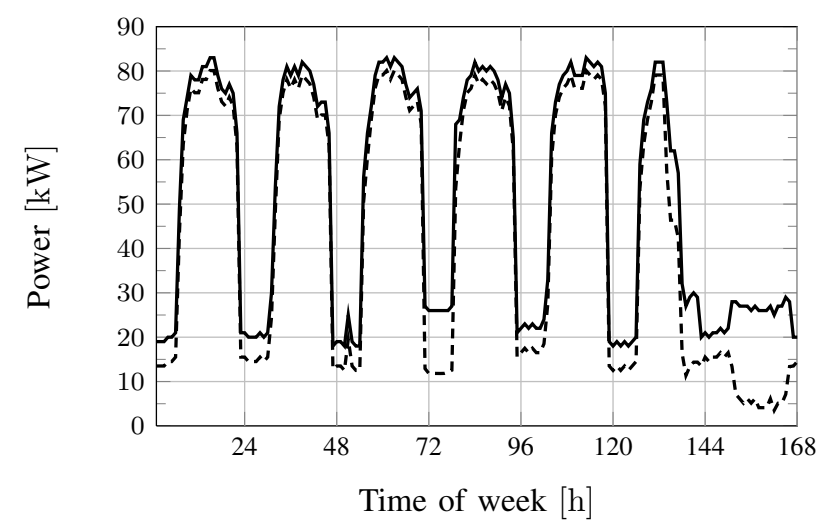

Fig. 4. Weekly power demand of the library, with and without (dashed line) the useless electricity consumption.

\section{RESUltS AND Discussion OF OTHER CASE STUdies}

The profile-based approach is applied on five different types of buildings at the University of Leuven: a library, a college building, an office building, a laboratory and a student residence. The share of useless electricity consumption accounts for $4-13 \%$ of the total electricity consumption of the respective buildings. Table II gives the share of useless electricity consumption in the total weekly electricity consumption of each of these five buildings. Table III gives a detailed overview of the useless electricity consumption for the five reference buildings.

The college building and laboratory represent buildings where education activities are combined with research activities. The share of useless electricity consumption in the total electricity consumption of the investigated buildings is significantly lower than for the case of the library or the office building. This is due to the fact that HVAC and ICT contribute to useless electricity consumption in the library and the office building, but not in the college building or the laboratory. In the college building and the library, there are some rooms that need to be acclimatized continuously. For both the library and office building, it was noted that there were some superfluous servers (ICT) and that these buildings were also heated outside the opening and/or working hours. Without these two mentioned losses, the share of useless
TABLE II

OVERVIEW OF THE WEEKLY ELECTRICITY CONSUMPTION AND SHARE OF THE USELESS ELECTRICITY CONSUMPTION IN THE FIVE REFERENCE BUILDINGS.

\begin{tabular}{lrc}
\hline Building & $\begin{array}{r}\text { Weekly electricity } \\
\text { consumption }\end{array}$ & $\begin{array}{c}\text { Share of useless } \\
\text { electricity consumption }\end{array}$ \\
\hline Library & $8554 \mathrm{kWh}$ & $13 \%$ \\
College building & $57974 \mathrm{kWh}$ & $5 \%$ \\
Office building & $21661 \mathrm{kWh}$ & $13 \%$ \\
Laboratory & $18474 \mathrm{kWh}$ & $4 \%$ \\
Student residence & $10351 \mathrm{kWh}$ & $13 \%$ \\
\hline Total & $117014 \mathrm{kWh}$ & $8 \%$ \\
\hline
\end{tabular}

electricity consumption drops to respectively $5 \%$ and $3 \%$ for the library and office building. These numbers are more in line with the college building and laboratory.

The student residence is different from the other buildings, as the major activity in this buildings differs and is shifted in time compared to the other buildings. The major contribution to the useless electricity consumption in student residences is due to electrical appliances in student rooms.

The screening of the buildings has shown that the activities and the behavior of the employees in the building have a large impact on the useless electricity consumption. Therefore, it is difficult to extrapolate these results for similar buildings. The investigated buildings represent about $12 \%$ of the electricity consumption of the university. This means that the useless electricity consumption of these five buildings amounts to about $1 \%$ of the total electricity consumption of the university.

\section{CONCLUSION}

Useless electricity consumption is the electricity consumption of an electric appliance or system whenever it is not performing its primary function or whenever it is performing its primary function without being useful. The large amount of energy consumed during the weekend and the large base load presume that useless electricity consumption could be responsible for a significant amount of the electricity consumption at the KU Leuven.

Earlier studies mainly focus on only standby losses as useless electricity consumption, or all electricitiy consumption outside e.g. working hours is considered as useless power in office buildings, etc. Therefore, there is a need for a general approach to identify the useless electricity consumption.

A profile-based approach is discussed to investigate the useless electricity consumption in buildings. This is done by setting up a profile for each individual appliance in the building, which gives the power demand of the appliance during a certain period. An analysis of this profile can identify whenever the electricity consumption was useful or useless, making it possible to give an indication of the useless electricity consumption of each appliance. By combining the results for all appliances or systems in the building, it is possible to determine the total useless electricity consumption.

This profile-based approach is applied to five different buildings at the KU Leuven as a case study. The profile-based 
TABLE III

OVERVIEW OF THE USELESS ELECTRICITY CONSUMPTION OF THE FIVE REFERENCE BUILDINGS. ALSO, THE USELESS ELECTRICITY CONSUMPTION FOR EACH CATEGORY, INCLUDING THE SHARE IN THE TOTAL USELESS ELECTRICITY CONSUMPTION, IS GIVEN.

\begin{tabular}{l|rr|rr|rr|rr|r|r|r}
\hline Building & \multicolumn{2}{|c|}{ ICT } & \multicolumn{2}{|c|}{ Public } & \multicolumn{2}{|c|}{ Non-public } & \multicolumn{2}{c|}{ HVAC } & \multicolumn{2}{c|}{ Lighting } & Total \\
\hline & {$[\mathrm{kWh}]$} & {$[\%]$} & {$[\mathrm{kWh}]$} & {$[\%]$} & {$[\mathrm{kWh}]$} & {$[\%]$} & {$[\mathrm{kWh}]$} & {$[\%]$} & {$[\mathrm{kWh}]$} & {$[\%]$} & {$[\mathrm{kWh}]$} \\
\hline Library & 480 & 43 & 126 & 11 & 101 & 9 & 242 & 22 & 166 & 15 & 1115 \\
College building & 0 & 0 & 307 & 10 & 1401 & 47 & 0 & 0 & 1260 & 43 & 2968 \\
Office building & 386 & 14 & 124 & 4 & 197 & 7 & 1836 & 64 & 324 & 11 & 2867 \\
Laboratory & 0 & 0 & 26 & 3 & 148 & 19 & 0 & 0 & 615 & 78 & 789 \\
Student residence & - & - & 12 & 1 & 700 & 53 & 0 & 0 & 605 & 46 & 1317 \\
\hline
\end{tabular}

approach shows that useless electricity consumption in the investigated library, college building, office building, laboratory and student residence accounts for respectively $13 \%, 5 \%, 13 \%, 4 \%$ and $13 \%$ of the total electricity consumption in the respective building. The large impact of the activities and the behavior of the employees in the building makes it however difficult to extrapolate the results for similar buildings. Nevertheless, the investigated buildings represent about $12 \%$ of the electricity consumption of the university. This means that the useless electricity consumption of these five buildings amounts to about $1 \%$ of the total electricity consumption of the university.

\section{ACKNOWLEDGMENT}

The authors would like to thank the technical services of the $\mathrm{KU}$ Leuven and the employees of the respective buildings for their cooperation in the investigation on standby and the other useless electricity consumption in the investigated buildings as part of the Master's Thesis of R. De Koster [12].

J. Van Roy is funded through a doctoral scholarship of the Flemish Institute for Technological Research (VITO) and through the PhD School of EIT-KIC InnoEnergy.

\section{REFERENCES}

[1] The European Commission. (2012) The EU climate and energy package. [Online]. Available: http://ec.europa.eu/clima/policies/package/ index_en.htm

[2] "Directive 2010/31/EU of the European Parliament and the Council on 19 May 2010 on the energy performance of buildings (recast)," The European Parliament, 2010.
[3] International Energy Agency, Things that go Blip in the Night: Standby Power and How to Limit it. Paris, France: OECD, 2001, ISBN 978926419275-1.

[4] B. Lebot, A. Meier, and A. Anglade, "Global Implications of Standby Power Use," in Proc. of ACEEE Summer Study on Energy Efficiency in Buildings, California, United States, Jun. 2000, pp. 1-11.

[5] K. Clement, I. Pardon, and J. Driesen, "Standby Power Consumption in Belgium," in 9th Int. Conf. on Electrical Power Quality and Utilization, Lodz, Poland, Oct. 9-11, 2007, pp. 1-4.

[6] EURECO, "Demand-side management, End-use metering campaign in 400 households of the European Community, Assessment of the potential electricity savings," Project EURECO, for the Commission of the European Communities, SAVE Contract No. 4.1031/Z/98-267, Jan. 2002.

[7] J.P. Ross, and A. Meier, "Measurements of whole-house standby power consumption in California homes," Energy, vol. 27, pp. 861-868, Sep. 2000.

[8] U.P. Menti, "Standby Verbrauch von Dienstleistungsgebuden," Sep. 1999, Study for the Swiss Federal Office of Energy.

[9] A. Meier, and B. Lebot, "One watt initiative: a global effort to reduce leaking electricity," May 1999, Lawrence Berkeley National Laboratory.

[10] "Commission Regulation (EC) No 1275/2008 of 17 December 2008 implementing Directive 2005/32/EC of the European Parliament and of the Council with regard to ecodesign requirements for standby and off mode electric power consumption of electrical and electronic household and office equipment," The European Commission, Dec. 2008.

[11] N.F. Nissen, "Standby and Off-mode Losses," Study carried out by Fraunhofer IZM on behalf of the European Commission, Berlin, Germany, Oct. 2007.

[12] R. De Koster, "Onderzoek naar het sluipverbruik van de Katholieke Universiteit Leuven (Research on stand-by power consumption in the Catholic University of Leuven)," Master's thesis, KU Leuven, Jul. 2011.

[13] K. Clement, E. Haesen, and J. Driesen, "The Impact of Charging Plug-In Hybrid Electric Vehicles on a Residential Distribution Grid," IEEE Trans. on Power Syst., vol. 25, no. 1, pp. 371-380, Feb. 2010. 